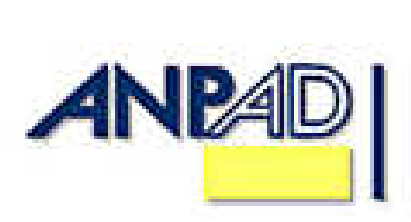

Disponível em

http://www.anpad.org.br/rac

RAC, Curitiba, v. 15, n. 5, art. 4,

pp. 855-876, Set./Out. 2011

(oc) EY-No

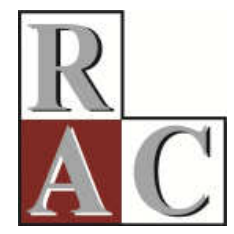

\title{
Entre o Planejamento Estratégico Formal e Informal: um Estudo de Caso Exploratório sobre a Prática de Estratégia nas Organizações
}

Between Formal and Informal Strategic Planning: an Exploratory Case Study on the Practice of Strategy in Organizations

Caio Motta Luiz de Souza *

E-mail: cmlsouza@gvmail.br Fundação Getulio Vargas - EAESP/FGV

São Paulo, SP, Brasil.

Copyright (C) 2011 RAC. Todos os direitos, até mesmo de tradução, são reservados. É permitido citar parte de artigos sem autorização prévia, desde que seja identificada a fonte. 


\title{
Resumo
}

Grande parte dos estudos sobre formação estratégica possui um elemento contingencial constitutivo que estabelece variáveis por meio das quais é possível ordenar as organizações de forma a indicar qual o tipo de formação estratégica é adequada a cada uma delas (e.g. Mintzberg \& McHugh, 1985). Esta ordenação quase prescritiva sobre o conteúdo, o processo e a prática de estratégia nas organizações pode causar a percepção de que é possível determinar o padrão de formação estratégica de uma organização pela simples análise de algumas variáveis pré-determinadas. Guiado pela abordagem de estratégia como prática (Jarzabkowski, 2005, 2008; Whittington, 1996, 2006), este trabalho explora a prática de planejamento estratégico com base num estudo de caso exploratório em uma empresa organizada por projetos, por meio do qual foi possível identificar processos de mudança que configuraram diferentes fases de aplicação dessa prática ao longo dos anos com características distintas de (in)formalidade. Analisando o caso por meio uma abordagem baseada na teoria da estruturação (Giddens, 1984), indica-se que, se há um nível adequado de formalização da prática de planejamento estratégico nas organizações, este nível deve ser definido pela estruturação da prática na sua dinâmica social.

Palavras-chave: estratégia como prática; planejamento estratégico; organizações baseadas em projetos; processos de mudança; formalização.

\begin{abstract}
Most studies on strategy formation have a constitutive contingency element that defines variables through which one could sort organizations into a certain order to indicate what type of strategy formation is more suitable for each (e.g. Mintzberg \& McHugh, 1985). This almost prescriptive ordinance concerning the content, process and practice of strategy in organizations can lead one to the perception that it is possible to determine the pattern of strategy of formation in organizations through the simple analysis of some predetermined variables. Guided by the strategy-as-practice approach (Jarzabkowski, 2005, 2008; Whittington, 1996, 2006), this paper explores the practice of strategic planning based on an exploratory single case study in a project-based organization, through which it was possible to identify change processes that shaped different stages of the strategic planning practice over the years with distinct characteristics regarding its (in)formality. These processes were analyzed using an approach inspired on the structuration theory (Giddens, 1984), indicating that the adequate level of strategic planning formalization should be defined by the structuration of practice in its social dynamic.
\end{abstract}

Key words: strategy-as-practice; strategic planning; project-based organization; change processes; formalization. 


\section{Introdução}

Ao analisar os estudos tradicionais do campo de estratégia, pode-se identificar um componente contingencial constitutivo em suas elaborações teóricas. Desde estudos clássicos, como o de Chandler (1962), que lida com a idéia de que a estrutura da organização deve corresponder à sua estratégia, até mesmo os trabalhos da perspectiva de escolha estratégica, nos quais a estrutura é determinada por suas contingências operacionais (Child, 1972), há um pressuposto de que é possível ordenar as organizações em um continuum de pontos de encaixe (fit), de acordo com a dimensão que é analisada (Donaldson, 2001). Um exemplo é o continuum entre estruturas orgânicas e mecânicas, de acordo com o nível de incerteza do ambiente (Burns \& Stalker, 1961). Essa característica contingencial também pode ser identificada nos estudos de formação estratégica (Mintzberg, 1978, 1993), que postulam uma relação ordenada entre determinadas características das organizações e o tipo de formação estratégica que se encaixa em cada uma delas.

Esta ordenação quase prescritiva sobre conteúdo, processo e prática de estratégia nas organizações pode causar a percepção de que é possível determinar qual é o padrão de formação estratégica de uma organização (e.g. Mintzberg, 1993) pela análise de variáveis predeterminadas, como a turbulência do ambiente da organização (Lawrence \& Lorsch, 1973), o nível de incerteza nos negócios (Burns \& Stalker, 1961), o tipo de tecnologia de produção empregado (Woodward, 1977).

Guiados pela abordagem de estratégia como prática, elaboramos um estudo de caso exploratório em uma empresa organizada por projetos, buscando observar seu processo de formulação e implementação de planejamento estratégico, no qual se esperaria um processo pouco estruturado de tomada de decisão de estratégia, aproximando-se de uma adhocracia (Mintzberg \& McHugh, 1985).

As evidências obtidas no estudo de caso mostraram um gap teórico, que foi identificado em nossa análise por uma abordagem baseada na teoria da estruturação (Giddens, 1984). No sentido oposto das expectativas teóricas, pudemos observar diversas fases de formalização do planejamento longo da história da organização e que, apesar de uma tendência informal evidenciada pela flexibilização dos processos em períodos subseqüentes, percebemos que diversos mecanismos formais permaneceram em operação na prática da empresa, sendo componentes recursivos importantes para o desenvolvimento da estratégia na organização (Machado-da-Silva, Fonseca, \& Crubellate, 2005). Neste contexto, destaca-se a importância da dinâmica organizacional para a compreensão de como ocorre a prática de estratégia e por que ela assume determinadas características formais ou informais ao longo do tempo nas organizações.

\section{O Lugar da Prática nos Estudos de Estratégia e Organização}

A origem da discussão sobre estratégia no campo da gestão é controvertida, mas pode-se dizer que, desde o início do século XX, já ocorriam debates ao redor do tema nas universidades (Ghemawat, 2002). No entanto, autores importantes consideram que a estratégia como disciplina de estudo da administração tem seu início com os trabalhos basilares de Alfred Chandler (1962), Kenneth R. Andrews (1971), e H. Igor Ansoff (1965) e Rumelt, Schendel e Teece (1994). A estruturação inicial desta área foi complementada pelo desenvolvimento e disseminação de conceitos e ferramentas de análise estratégica; tanto por acadêmicos (e.g. Modelo de cinco forças desenvolvido por Porter), como por consultorias (e.g. matriz growth-share desenvolvida pela BCG) (Ghemawat, 2002), além da criação de instituições representativas do campo de estratégia, por exemplo, a Strategic Management Society (SMS). Durante estes quase 50 anos, diversas de teorias e abordagens foram criadas para o estudo dos fenômenos ligados ao campo da estratégia.

De forma geral, os primeiros estudos do campo inspiraram um tipo de pesquisa que buscou definir o conteúdo da estratégia, isto é, compreender o que é necessário saber para traçar a estratégia 
correta de determinada organização, algo usualmente feito pela criação de tipologias analíticas (Chia \& Mckay, 2007; Whittington, 1996). Entre os representantes dessa linha temos o trabalho sobre definição de estratégia corporativa de Ansoff (1965), as análises econômicas sobre estratégia e estrutura de Rumelt (1974) e os trabalhos sobre estratégia competitiva de Porter (1980). Apesar da utilidade das ferramentas de análise criadas para o trabalho dos estrategistas, a principal crítica a essa abordagem é que ela ignora a complexidade da aplicação da estratégia nas organizações.

Ao olhar a estratégia somente por essa perspectiva de conteúdo, é difícil ver a sua relação com questões organizacionais. Apesar do estudo de Chandler (1962) já trabalhar com a noção de estratégia e estrutura, a relação estabelecida entre estes conceitos é praticamente de subordinação da estrutura às decisões econômicas da estratégia organizacional. Dessa forma, com a elevada importância dada a essas decisões, a corrente principal do campo de estratégia passou a enfatizar as questões econômicas e ambientais que envolviam as corporações. Porém, já no início da década de 1980, começou-se a desenvolver perspectivas alternativas que promovem a convergência entre estratégia e teoria organizacional (Vasconcelos \& Cyrino, 2000).

Segundo os autores, uma dessas aproximações ocorre com o surgimento da chamada visão baseada em recursos (Resource Based View [RBV]). A RBV, guiada pelo trabalho precursor de Birger Wernerfelt (1984) e aprofundada por outros autores, como Jay Barney (1986a; 1986b), foi um marco na reaproximação entre estes dois campos (estratégia e organização), depois do predomínio dos estudos inspirados na organização industrial de Joe Bain (industrial organization) aprofundados por Porter no final da década de 1970 (Ghemawat, 2002) e teve suas bases em pelo menos três precursores. Um deles é a escola de design estratégico, que estrutura o modelo de análise SWOT (Andrews, 1971) e que discute tanto fatores externos como internos da organização. Outro precursor é o trabalho de Edith Penrose (1959), que definiu as firmas como um feixe de recursos, destacando a importância das restrições internas ao crescimento da firma. O terceiro precursor é o trabalho sobre teoria institucional de Philip Selznick (1966), no qual organizações institucionalizadas de Selznick detêm um recurso com as características descritas por Barney, algo que é construído pela organização ao longo dos anos e que se torna vantagem competitiva. Em suma, instituições podem ser pensadas como recurso(s), territórios por meio dos quais as empresas detentoras, usufruiriam de rendas ricardianas (Vasconcelos \& Cyrino, 2000).

Outra abordagem que também surge no campo de estratégia, que a aproxima dos estudos organizacionais, é a processual; esta que difere substancialmente da ideia de conteúdos, pois direciona seu foco para a análise do cotidiano da formação estratégica (Mintzberg, 1978). O objetivo da abordagem processual é compreender como a estratégia é criada e realizada na organização. Usualmente os resultados desses estudos são análises da dinâmica interna das organizações ao definir, implementar e alterar sua estratégia (Johnson, 1987; Pettigrew, 1985), demonstrando processos de emergência dos planos (Mintzberg \& Waters, 1985), apontando os limites do planejamento (Pettigrew, 1985), e a reduzida importância de processos formais de definição de estratégia (Mintzberg \& McHugh, 1985), a ponto de declarar até mesmo o declínio da prática de planejamento estratégico (Mintzberg, 1994).

Apesar do grande apelo dessa abordagem, a principal crítica levantada é que, por haver uma predominância de uma visão macro sobre a estratégia das organizações (Chia \& Mckay, 2007), a perspectiva processual dá menos ênfase aos microprocessos envolvidos no desenvolvimento das estratégias e marginaliza ferramentas, atividades e práticas que são utilizadas pelos profissionais em seu cotidiano (Jarzabkowski, 2005; Whittington, 1996). Soma-se a isso a ênfase no processo e na emergência da estratégia, o que mina o poder de agência dos profissionais, na medida em que considera que todos estão à mercê do processo da estratégia (Jarzabkowski, 2008; Whittington, 2006).

Como tentativa de resposta a esse problema, surge a abordagem de estratégia como prática. Sob a inspiração da chamada virada prática nas ciências sociais (Schatzki, Knorr-Cetina, \& Savigny, 2001), esta abordagem busca compreender a estratégia como algo (re)definido pela interação das práticas de estratégia com profissionais envolvidos e execução dos planos no cotidiano. Esse 
movimento teórico, apesar de ter suas raízes nas primeiras análises de Richard Whittington (1996), só ganhou espaço recentemente.

Há dois fatores principais vinculados à emergência deste movimento no campo de estratégia (Jarzabkowski, 2005). O primeiro deriva da limitação do modelo clássico de elaboração de conhecimento na área, que reduz a multiplicidade envolvida no fazer estratégia a poucas variáveis, na maioria das vezes econômicas, isto é, uma tentativa de resposta às teorias de estratégia como conteúdo. O segundo fator é a pouca importância dada aos estrategistas, subestimados tanto nas abordagens de conteúdo como de processo.

Gradualmente, surgiram pesquisas e análises que buscavam incluir o trabalho dos sujeitos nos estudos, trazendo a noção de que, ao invés de estudar organizações, as pesquisas deveriam ser direcionadas ao organizar (organizing) (Weick, 1979) ou estrategizar (strategizing) (Jarzabkowski, Balogun, \& Seidl, 2007), buscando as filigranas da estratégia (Whittington, 1996) e os pixels da influência gerencial (Jarzabkowski, 2008).

Os estudos que utilizam esta abordagem buscam compreender estratégia como atividade situada em contexto e efetivada socialmente, entendendo como prática a ação dos sujeitos e os diferentes procedimentos, rotinas e ferramentas utilizadas na sua interação (Jarzabkowski et al., 2007). Assim, a estratégia como prática é uma abordagem que propicia a observação da relação entre a perspectiva micro do cotidiano do estrategista e a perspectiva macro das práticas definidas para elaboração da estratégia, o que possibilita explorar como essa relação opera.

Mesmo sendo nova, esta abordagem não escapa de críticas. Carter, Clegg e Kornberger (2008) questionam contundentemente a estratégia como prática, indicando as inconsistências nos conceitos de estratégia e prática utilizados nos estudos. Apesar da crítica dos autores ser pertinente, é esperado que, dentro de uma abordagem nova, haja dissonâncias ao invés de se constituir imediatamente como um corpo teórico monolítico: a estratégia como prática está em meio a um esforço de exploration (March, 1991).

Para consolidar nossa discussão sobre o lugar da estratégia como prática, lançamos mão de uma divisão útil elaborada por Chia e Mckay (2007) como uma tentativa de organizar o campo e suas diferentes abordagens em três perspectivas de análise (cf. Tabela 1).

Tabela 1

Três Abordagens para o Estudo da Estratégia

\begin{tabular}{|c|c|c|c|}
\hline Abordagem & Conteúdo de Estratégia & Processo de Estratégia & Estratégia como Prática \\
\hline Foco de Análise & $\begin{array}{l}\text { Qual é a estratégia correta } \\
\text { para uma organização? }\end{array}$ & $\begin{array}{l}\text { Como a estratégia é criada e } \\
\text { realizada? }\end{array}$ & $\begin{array}{l}\text { Como a estratégia (re)definida } \\
\text { durante sua execução pelos } \\
\text { profissionais e ferramentas } \\
\text { envolvidas? }\end{array}$ \\
\hline $\begin{array}{l}\text { Principal } \\
\text { Benefício }\end{array}$ & $\begin{array}{l}\text { Fornece tipologias } \\
\text { analíticas úteis }\end{array}$ & $\begin{array}{l}\text { Captura a dinâmica interna das } \\
\text { organizações ao definir a } \\
\text { estratégia }\end{array}$ & $\begin{array}{l}\text { Observa a inter-relação de } \\
\text { gerentes, práticas e prática } \\
\text { cotidiana na construção da } \\
\text { estratégia. }\end{array}$ \\
\hline Principal Crítica & $\begin{array}{l}\text { Ignora a complexidade da } \\
\text { aplicação da estratégia }\end{array}$ & $\begin{array}{l}\text { Foco em macro-processos } \\
\text { marginaliza as ferramentas, } \\
\text { atividades práticas e o poder de } \\
\text { agência dos profissionais }\end{array}$ & $\begin{array}{l}\text { Problemas na definição de } \\
\text { conceitos fundamentais para a } \\
\text { estruturação dos estudos. }\end{array}$ \\
\hline $\begin{array}{l}\text { Trabalhos } \\
\text { Fundamentais }\end{array}$ & $\begin{array}{l}\text { Ansoff (1965); Andrews } \\
\text { (1971); Porter (1980); } \\
\text { Rumelt (1974) }\end{array}$ & $\begin{array}{l}\text { Mintzberg (1978, 1994); } \\
\text { Pettigrew (1985); Johnson } \\
\text { (1987) }\end{array}$ & $\begin{array}{l}\text { Whittington }(1996,2006) \text {; } \\
\text { Jarzabkowski }(2005)\end{array}$ \\
\hline
\end{tabular}

Nota. Fonte: Elaborado pelo autor. 


\section{Uma Abordagem para o Estudo da Prática}

Um dos maiores desafios enfrentados pelos acadêmicos que pesquisam a prática é encontrar uma abordagem teórico-metodológica adequada, que consiga dar conta de mudanças, levando em conta uma relação tríplice entre profissionais, práticas formalizadas e práxis, sendo esta "a interconexão entre ações de indivíduos e grupos diferentes e dispersos e instituições incorporadas [embedded] de forma social, política e econômica na qual indivíduos agem e contribuem" (Jarzabkowski et al., 2007, p. 9). A explicação dessa relação tem animado alguns trabalhos que buscam desenvolver formas de lidar com essa questão.

Muitos desses autores baseiam-se na teoria da estruturação (Giddens, 1984), para realizar suas análises (e.g. Barley \& Tolbert, 1997; Jarzabkowski, 2008; Orlikowski, 2000; Whittington, 2006). O amplo uso das idéias de Giddens (1984) é compreensível porque, diferentemente das abordagens institucionalistas (DiMaggio \& Powell, 1983; Meyer \& Rowan, 1977), que exploram a difusão e uso de práticas pelas organizações por pressões institucionais, sua teoria possibilita explorar como a dinâmica social das organizações impacta nas práticas definidas para a análise estratégica, pois abre espaço para o processo subjacente (micro) relacionado ao fenômeno de interesse, incluindo a agência dos sujeitos dentro da formação das estruturas constitutivas dos sistemas sociais (Whittington, 2006).

Para possibilitar análises que deem relevância a processos subjacentes, Giddens converte o dualismo de sociedade e indivíduo, em uma dualidade entre estrutura e agência (Cohen, 1987). Essa diferenciação é crucial, porquanto, ao estabelecer a dualidade, Giddens habilita a possibilidade da recursividade entre agência e estrutura, isto é, o agente tem sua ação moldada pela estrutura que, ao mesmo tempo, restringe e habilita sua ação. No entanto o agente, em sua prática cotidiana, também molda a estrutura e a repetição (recursiva) desse processo ao longo do tempo constitui os sistemas sociais, propiciando a sua estruturação. Para ele:

A constituição de agentes e estruturas não é um fenômeno constituído de dois conjuntos separados de agentes e estruturas, um dualismo, mas representam uma dualidade [...] as propriedades estruturais dos sistemas sociais são tanto um meio como o resultado das práticas que eles organizam. A estrutura não é externa ao indivíduo: é concretizada (instantiated) nas práticas sociais e, em certo sentido, mais interno que externo das atividades em um sentido Durkheimiano. A estrutura não deve ser equacionada somente como restrição, mas algo que restringe e habilita [constraining and enabling] (Giddens, 1984, p. 27).

Esta teoria pressupõe a estruturação como processo dinâmico, o que torna difícil identificar isoladamente os conceitos que a delineiam. A separação dos conceitos envolvidos é feita por motivos metodológicos. Os quatro conceitos fundamentais para a análise da estruturação são: estruturas, interação, modalidades e eventos.

As estruturas são organizadas como propriedades dos sistemas sociais, isto é, elas não existem senão de forma virtual e só se concretizam como tal quando são aplicadas pelos agentes em sua ação. Apesar de também ser possível referir-se às estruturas como princípios de organização da sociedade ou características institucionalizadas de sistemas sociais ao longo do tempo, a noção de estrutura que nos interessa no momento é definida por regras e recursos envolvidos na articulação dos sistemas sociais. Por regras que constituem as estruturas, podemos entender os procedimentos metodológicos da interação social; estão ligadas, principalmente, às dimensões de significação e legitimação das estruturas. Os recursos podem ter duas características: (a) alocativa, vinculada a objetos materiais; e (b) impositiva, que se refere ao controle de pessoas, e estas estão conectadas à dimensão de dominação das estruturas.

A interação é a ação realizada pelos agentes e esta é restringida e habilitada pelas estruturas concretizadas em episódios. Dentro da interação, o poder de agência dos sujeitos é uma condição para a recursividade, pois confere àqueles envolvidos na ação a capacidade de transformação das estruturas, mesmo que esta transformação não seja necessariamente intencional (estratégica). 
A conexão entre as estruturas e o campo de interação não é direta, pois nenhuma ação se expressa ou pode ser explicada em termos de uma regra ou recurso, mas por conjuntos de regras e recursos. Assim, para habilitar a recursividade de seu modelo, Giddens elabora uma ligação entre os domínios de estrutura e interação por meio da noção de modalidades que são o meio de reprodução de componentes estruturais de sistemas de interação, mas que também são alteradas pelos próprios agentes. As modalidades são tratadas como conjunto de conhecimentos e recursos empregados por atores na constituição da interação como um feito habilidoso e informado, sob condições limitadas de racionalização (Giddens, 1984).

O último conceito que consideramos importante destacar são os eventos. Embora esta ideia não esteja desenvolvida nos trabalhos de Giddens, alguns autores buscaram conceituar essa ideia para colaborar com a definição de uma unidade de análise que pudesse identificar pontos de alteração dentro da dinâmica de construção de instituições. Os eventos podem ter diversas formas: desde reuniões formais da diretoria até conversas cotidianas. Dijk (2000) descreve a noção de episódio, ou evento, como algo intuitivo e, às vezes, trivial no cotidiano. Como episódio de uma história, o evento é tanto parte de um todo (da história), como também tem delimitação própria, com início e fim (Dijk, 2000).

Os eventos representam momentos de recursividade entre agência e estrutura, que garante a possibilidade (e ocorrência) de mudanças nas modalidades; mas, para isso, a interiorização das práticas pelos atores deve ser abalada, possibilitando que sua ação seja contrária a estas práticas legitimadas (Machado-da-Silva et al., 2005), causando uma mudança ou, pelo menos, disposição à mudança. Nesse processo também pode ocorrer a alteração de estruturas: seja pela criação e adoção de novas práticas (recursos), seja pela aplicação de novas lógicas de pensamento e ação (regras) (Jarzabkowski, 2008; Whittington, 2006).

Aplicar essa abordagem em pesquisas sobre estratégia e organizações não é uma tarefa simples, principalmente por lidar com a relação simultânea de ação e estrutura. Somado a isso, a teoria foi desenvolvida tendo em mente sistemas sociais amplos, e não organizações singulares (e.g. empresas).

No entanto alguns pesquisadores buscam utilizar tal abordagem para analisar questões organizacionais, a exemplo de Barley e Tolbert (1997), que elaboram um esquema que adapta a teoria de Giddens. A denominação dada aos elementos conceituais da teoria de Giddens varia de acordo com o autor e os referenciais utilizados (Barley \& Tolbert, 1997; Jarzabkowski, 2008; Orlikowski, 2000; Whittington, 2006).

Neste trabalho, entenderemos por agentes os profissionais da organização que interagem no trabalho de (re)definição da estratégia da organização. Esses profissionais realizam diversas práticas e estas podem ser representadas como modalidades da organização, ou seja, as atividades e padrões de interação observáveis (Barley \& Tolbert, 1997; Rose, 2006). A noção de prática utilizada para indicar modalidades deve ser tomada em sentido amplo, como conjuntos de estruturas de significados, habilidades e normas; como, por exemplo, a prática de planejamento estratégico (e não seu ciclo anual), prática de gestão de projetos, entre outras.

$\mathrm{Na}$ concretização dessas práticas em eventos, os profissionais fazem uso de estruturas que contêm um conjunto de procedimentos, rotinas, ferramentas (i.e. recursos) e regras, envolvidas na formação das práticas da empresa. Estas estruturas compreendem tanto rotinas, ferramentas e discursos criados internamente como aqueles criados fora da organização e que podem ser interiorizados por algum motivo (e.g. reuniões de brainstorming, metodologia balanced scorecard; discursos de busca da excelência). 


\section{Método}

O método selecionado para este trabalho foi o estudo de caso único e exploratório (e.g. Balogun \& Johnson, 2005; Selznick, 1966).

Apesar do entendimento comum de que um estudo de caso único não pode fornecer informações confiáveis para a generalização e pode ser útil apenas para estágios preliminares de investigação (Eisenhardt, 1989; Eisenhardt \& Graebner, 2007), há crescente literatura que busca retomar o valor do estudo de caso único (Bitektine, 2008; Dyer \& Wilkins, 1991; Flyvbjerg, 2006; Langley, 1999). Um dos principais argumentos para retomar estudos com base neste método é que o estudo de caso único é ideal para o desenvolvimento de conhecimentos que dependam da análise contextual.

Este argumento é reforçado, quando se trata da análise de casos específicos que, muitas vezes, contrariam pressupostos teóricos estabelecidos, como as metáforas do porco que fala (Siggelkow, 2007) ou dos cisnes negros (Flyvbjerg, 2006), visto que, devido à sua profundidade, as análises operadas na pesquisa de um único caso podem evidenciar características especiais que desconhecem determinado fenômeno. De acordo com Siggelkow (2007), "se a teoria conversa somente com a teoria, o exercício coletivo da pesquisa corre o perigo de tornar-se totalmente autorreferenciado e fora de contato com a realidade, podendo ser considerado irrelevante" (p. 23, Tradução nossa).

Dessa forma, o estudo de caso único é estratégia de pesquisa que possibilita maior profundidade de análise, o que pode evidenciar características especiais ou que desconhecem determinado fenômeno (Flyvbjerg, 2006), e permitem a eventual emergência de novas ideias e proposições (Bitektine, 2008; Siggelkow, 2007).

Tendo em mente esta discussão sobre os diferentes estudos de caso únicos e suas contribuições, procuramos escolher uma empresa que possibilitasse uma análise rica para este trabalho. Selecionamos uma empresa de gestão de projetos de engenharia (InfraCo), para ser o objeto de nosso estudo de caso exploratório. Esta empresa tem estrutura baseada em projetos; recentemente, recebeu um prêmio que certificou a excelência e qualidade de seu modelo de gestão. Esta característica chamou nossa atenção por contrariar as expectativas teóricas ligadas a uma organização estruturada e baseada em projetos ( $c f$. Mintzberg \& McHugh, 1985), já que a empresa estudada buscou desenvolver um modelo formal de gestão para guiar suas ações, enquanto o esperado seria manter-se menos estruturada para atender a seus clientes e se adaptar ao ambiente de forma ad hoc.

Como recorte do estudo, escolhemos a prática de formulação da estratégia corporativa e as ferramentas estabelecidas para sua realização, em especial o ciclo de planejamento estratégico da empresa. Esse recorte foi feito tendo em vista: (a) a crescente relevância de estudos sobre ferramentas de estratégia na comunidade acadêmica internacional (Knott, 2006; Jarzabkowski \& Wilson, 2006); (b) a escassez de estudos empíricos sobre como as empresas organizam e realizam o planejamento estratégico (Grant, 2003) e, por outro lado; (c) a importância e o amplo uso desta ferramenta, algo evidenciado em pesquisas longitudinais em escala mundial, que o apontam como a prática mais utilizada pelas empresas (Rigby \& Bilodeau, 2007).

\section{Coleta de dados}

No estudo de caso, foram utilizadas três fontes de dados: (a) entrevistas com profissionais; (b) análise documental longitudinal; e (c) observação direta. Com estes dados foi possível não fixar a análise em apenas uma fonte, aproximando-nos de uma triangulação (Jick, 1979), para identificar as questões envolvidas no trabalho do planejamento estratégico.

A técnica de amostragem dos entrevistados foi oportunista, envolvendo um informante na indicação de pessoas-chave (Arksey \& Knight, 1999), o que possibilitou a cobertura de grande parte dos responsáveis pela realização do planejamento estratégico na empresa. 
Entrevistas semiestruturadas foram conduzidas com pessoas de diferentes níveis hierárquicos e áreas da organização, todas elas envolvidas na formulação das estratégias da empresa; depois de cada entrevista, avaliávamos os resultados obtidos e buscávamos aperfeiçoar o roteiro. Foram realizadas 16 entrevistas com 15 entrevistados, com duração média de 74 minutos, totalizando, aproximadamente 20 horas de gravação. A técnica de amostragem dos entrevistados foi oportunista, envolvendo o informante na indicação de pessoas-chave e no contato com estes candidatos da entrevista. A amostra foi composta por 8 mulheres e 7 homens, com formação básica em engenharia (12), administração (2), psicologia (1) e administração e engenharia (1). Para mais informações sobre o perfil dos entrevistados, ver Tabela 2.

Tabela 2

\section{Perfil dos Entrevistados}

\begin{tabular}{ccccc}
\hline ID & Cargo & Área & $\begin{array}{c}\text { Tempo na } \\
\text { Empresa }\end{array}$ & $\begin{array}{c}\text { Tempo de Envolvimento no } \\
\text { Planejamento }\end{array}$ \\
\hline E1 & Diretor & Comercial & $>20$ anos & $>10$ anos \\
E2 & Diretor & Comercial & $>20$ anos & $<5$ anos \\
E3 & Gerente & Área de Conhecimento & $<10$ anos & $<5$ anos \\
E4 & Diretor & Administrativa & $>20$ anos & $<5$ anos \\
E5 & Diretor & Área de Conhecimento & 10 a 20 anos & $<5$ anos \\
E6 & Gerente & Operacional & $>20$ anos & 5 a 10 anos \\
E7 & Analista & Administrativa & 10 a 20 anos & 5 a 10 anos \\
E8 & Diretor & Administrativa & $>20$ anos & 5 a 10 anos \\
E9 & Diretor & Comercial & $>20$ anos & $>10$ anos \\
E10 & Diretor & Administrativa & $>20$ anos & $<5$ anos \\
E11 & Diretor & Administrativa & $>20$ anos & $>10$ anos \\
E12 & Diretor & Área de Conhecimento & $>20$ anos & $<5$ anos \\
E13 & Gerente & Administrativa & 10 a 20 anos & 5 a 10 anos \\
E14 & Diretor & Administrativa & $<10$ anos & 5 a 10 anos \\
E15 & Analista & Administrativa & 10 a 20 anos & 5 a 10 anos \\
\hline
\end{tabular}

Nota. Fonte: Elaborado pelo autor.

A análise documental foi feita com base em dois tipos de documentos coletados para análise: (a) documentos internos da empresa; e (b) documentos de domínio público. Estes dados foram essenciais, pois possibilitaram uma contextualização mais rica do caso e aumentaram a confiabilidade dos dados obtidos nas entrevistas, já que documentos "são produtos 'em tempo' e componentes significativos do cotidiano; complementam, completam e competem com a narrativa e a memória" (Spink, 1999, p. 126).

Obtivemos aproximadamente 1.200 páginas de documentos internos com informações sobre o seguinte: metodologias utilizadas para o planejamento estratégico; planos estratégicos da empresa; informações sobre a implantação do modelo de gestão na empresa e outros inputs utilizados para o planejamento estratégico: e.g. apresentação de professor de uma renomada escola de negócios feita durante o planejamento de 2007. Além disso, tivemos acesso a modelos de planilha e todos templates de planejamento estratégico utilizados na empresa. Por motivos de confidencialidade, a maior parte dos documentos teve de ser analisada em visitas da empresa. 
No caso dos documentos de domínio público, foi realizada uma busca por notícias publicadas sobre a empresa durante um período de 10 anos na base de dados ISI Emerging Markets Information Service, para obter informações que pudessem corroborar com a pesquisa e contextualização do caso. Um documento que merece destaque, por sua importância em nossa análise, foi um estudo sobre o planejamento estratégico da empresa, publicado em um periódico internacional conceituado na área de estratégia, no qual se descreve o período de 1975 a 1984, inspirando grande parte das análises do artigo sobre esse período.

A observação direta, apesar de ser fonte rica de dados sobre o trabalho de formulação estratégica e ser amplamente utilizada em pesquisas da estratégia como prática (Chia \& Mckay, 2007), por questões de restrição de acesso e confidencialidade, só pôde ser realizada em uma ocasião: a reunião de apresentação do resultado final do planejamento para toda a empresa, quando estavam presentes o presidente da InfraCo e todos os presidentes das empresas associadas.

O resultado da observação foi somado a um diário de campo, que o pesquisador manteve para relatar suas observações sobre as visitas feitas à empresa (Czarniawska, 2008; Lofland \& Lofland, 1995). No final da coleta de dados o diário continha, aproximadamente, 30.000 palavras, descrevendo as percepções obtidas sobre diversos aspectos das visitas de campo e notas sobre os encontros com os entrevistados.

\section{Análise dos dados}

As entrevistas foram transcritas e inseridas em um software de análise de dados qualitativos (Atlas.ti), em conjunto com o diário de campo elaborado e os relatórios gerados a partir da análise de documentos. Todo o conjunto de dados obtido foi submetido à codificação temática para identificar temas e construtos-chave (Miles \& Huberman, 1994). Antes da codificação temática, códigos preliminares já tinham sido elaborados; porém a possibilidade de codificação aberta para o surgimento de novos temas foi mantida.

A partir desta análise, foi elaborada uma rede de relação entre os códigos criados para a descrição da empresa e aqueles vinculados ao planejamento estratégico da empresa. De acordo com a análise conjunta dos códigos previamente criados, os códigos que emergiram da análise dos dados e a rede criada entre os códigos, identificou-se um conjunto de temas relacionados ao seguinte: (a) fatores contextuais da empresa; (b) trabalho de planejamento estratégico; e (c) mudanças na prática de planejamento estratégico. Com base nos dados organizados nestes temas, buscou-se construir uma narrativa sobre o planejamento estratégico da empresa (Balogun \& Johnson, 2005; Langley, 1999). Essa análise foi capaz de identificar períodos nos quais houve mudanças no planejamento estratégico da empresa e nas práticas utilizadas.

\section{Resultados}

\section{$O$ caso: InfraCo}

A InfraCo é antiga e renomada empresa de serviços ligados a projetos de infraestrutura. A história da InfraCo é marcada pelas diversas oscilações dos ciclos de investimentos em infraestrutura brasileiros ( $c f$. Ferreira \& Malliagros, 1997). Consequentemente, enquanto alguns mercados em que a empresa atuava prosperavam, outros enfrentavam períodos extremamente difíceis. Esta característica é, provavelmente, um dos motivos da diversificação de sua atuação em tantas áreas distintas: e.g. energia, telecomunicações.

Durante o estudo de campo, a InfraCo passava por grande mudança organizacional, que descentralizou seus negócios em diferentes empresas, criando estruturas administrativas separadas para cada um de seus negócios, o que impactou a condução das atividades de todos os profissionais da 
empresa. Essa mudança impactou o estudo, uma vez que, apesar da maior parte dos dados coletados serem referentes a uma empresa específica, as fronteiras internas da InfraCo não estavam bem delimitadas: alguns dos entrevistados da pesquisa estavam em novos cargos, mas ainda acumulavam suas antigas funções da InfraCo em seu antigo formato.

$\mathrm{Na}$ época da coleta de dados, a empresa em que o estudo se concentrou contava com aproximadamente 700 funcionários e estava organizada sobre uma estrutura baseada em projetos (grupo-tarefa), representando metade do contingente de profissionais da InfraCo. Dentro desta estrutura, era comum o acúmulo de funções ou, como se referem na empresa: o acúmulo de vários chapéus (papéis) pelos profissionais; seja na parte de operações, como nas áreas de suporte.

\section{O planejamento estratégico na InfraCo}

A InfraCo sempre se inseriu em ambiente de negócios instável. Essa característica criou muitos desafios para a sustentabilidade da empresa e colaborou para tornar a estratégia de negócios uma preocupação antiga dentro da organização.

A InfraCo demonstrou a capacidade de se reinventar para surfar nas ondas do mercado criando soluções, muitas vezes inovações, e tendo um comportamento empreendedor em seus investimentos. É marcante que ela tenha perdurado no mercado por tantos anos, passando por diversas oscilações da economia, enquanto outras empresas concorrentes das primeiras décadas encerraram suas atividades. Apesar desta capacidade de adaptação ao mercado permear todo o histórico da empresa, ela nem sempre derivou de um planejamento estratégico formal.

Os primeiros planos estratégicos da empresa foram produzidos em 1975-76, quando a alta administração decidiu reavaliar seu rumo por ter identificado uma redução no ritmo de crescimento do negócio. A empresa tinha crescido muito, chegando a quase 2.000 funcionários e havia recentemente divisionalizado sua estrutura. Os planos resultantes deste esforço inicial não conseguiram mudar sua situação. Depois de duas tentativas experimentais, a organização contratou um grupo de consultores estrangeiros.

O exercício do planejamento na época buscou incluir o primeiro e segundo escalão da empresa e os 60 principais executivos. $\mathrm{O}$ trabalho desenvolvido mostrou-se custoso em termos de consumo de tempo das pessoas envolvidas na sua elaboração e com baixa efetividade de implementação. Assim, o esforço gerou uma ambivalência entre o entusiasmo e a boa vontade dos participantes na definição dos planos, em oposição à insatisfação, quando as decisões tomadas nos planos eram postergadas.

Nos anos seguintes, apesar do interesse na estratégia da empresa, havia a preocupação de não se perder em planos com diversas páginas, que ninguém lia nem aplicava. Dessa forma, os resultados do trabalho nunca estavam em um plano consolidado da InfraCo, pois existia a percepção de que as fortes turbulências vividas nos setores de atuação da empresa requeriam a reformulação contínua da estratégia. Assim, o trabalho de planejamento estava mais focado na reflexão sobre os rumos dos negócios da organização.

Nossos entrevistados não conheciam esta história. O conhecimento deles sobre o trabalho dos consultores, no final da década de 1970, se resumia numa lembrança sobre uma palestra ministrada pelo prof. Igor Ansoff, que havia sido gravada em vídeo, e que era na verdade o coordenador do grupo de consultores.

Para os entrevistados, o início exato da prática formal de planejamento estratégico na InfraCo foi difícil de precisar; mas os primeiros anos da década de 1990 foram apontados como um marco provável, pois a empresa passou por um momento importante com a decisão de encerrar suas atividades em determinado segmento, o que reforçou a percepção de necessidade de planejamento estratégico. Conforme um dos entrevistados relatou: 
"Eu tenho consciência que o primeiro formal foi em 1991... Nessa época que era justamente uma transição... O primeiro planejamento estratégico foi uma transição de mudança de público para privado" (Entrevistado 01).

Nesse período a prática do planejamento não tinha um formato definido, sendo descrita pelos entrevistados como livre. $\mathrm{O}$ que existia eram apenas algumas diretrizes como: quais serão seus objetivos e planos. A partir disso, cada área da empresa formulava as estratégias de forma independente. Alguns entrevistados mencionaram a existência de análises dos cenários econômicos e tendências do mercado; porém a maior parte era pouco estruturada.

Quando havia a consolidação dos planos elaborados, a intenção era a divulgação da estratégia da empresa aos profissionais em uma plenária, pois não era dada grande relevância à mensuração e acompanhamento do resultado do planejamento. $\mathrm{O}$ foco era muito mais voltado para estratégias de mercado, deixando menor espaço para questões relacionadas à estrutura e gestão interna da organização.

"Na época, era muito focado em 'que mercado nós vamos atacar? Que oportunidades que a gente vai perseguir?', muito mais do que uma estruturação da empresa com a gestão dela mesma propriamente dita. A gestão aparecia como problemas de outros e que quem estivesse lá [decidindo a estratégia] não precisava também sugerir, adequar... Era como se fosse uma coisa comprada e pronta, estava ali pronta e você não precisava mexer" (Entrevistado 05).

Esse formato de planejamento estratégico aparentemente continuou ao longo da década de 1990. Certamente o formato da prática não permaneceu idêntico, durante todo este período. Mudanças provavelmente aconteceram, mas só pudemos identificar uma alteração expressiva na forma de trabalho entre os anos de 2002 e 2003. Ao buscar informações sobre a situação dos negócios nesse período, percebemos que a empresa vivia uma ótima trajetória: tinha aumentado o número de profissionais de forma significante, tinha boas perspectivas em seus setores de atuação e os investimentos feitos tiveram resultados satisfatórios. O desempenho positivo da organização estimulou a InfraCo a planejar uma divisão em vários negócios separados de acordo com setor de atuação. No entanto, estes planos foram adiados.

Foram identificados pelo menos três fatores principais, que abalaram a organização na época. $\mathrm{O}$ primeiro fator foi o impacto da conjuntura macroeconômica sobre os contratos firmados pela empresa. O segundo foi o estouro da bolha da internet, algo que é diretamente ligado aos negócios de tecnologia da informação da InfraCo. O terceiro fator que surgiu foram os problemas enfrentados na execução dos projetos de engenharia naquele ano, mais especificamente em um projeto no qual a empresa se saiu muito mal. Esse ponto surgiu recorrentemente nas entrevistas, e parece ter sido o principal motivador da mobilização da organização.

"Um exemplo mais emblemático, mais profundo, aconteceu conosco em 2002, 2003, quando nós tivemos um projeto indo muito mal economicamente, muito mal. Isso provocou no ano de 2003 um prejuízo na organização. Em toda a história, só em dois anos ela teve prejuízo e um deles foi esse. Foi em 2003. Então, foi assim... marcante" (Entrevistado 04).

Esta situação vivenciada em 2003 gerou tanto uma sensação de fragilidade e incerteza em relação ao ambiente, como uma pressão interna sobre a gestão da empresa, pela percepção da dificuldade em alinhar os recursos da organização para atingir seus objetivos. Pudemos perceber que a pressão interna teve um impacto significativo, porque, como decorrência da estrutura societária da empresa, o prejuízo econômico gerou desconforto acima do normal, já que os profissionais recebem dividendos e distribuição de lucros como parte fundamental de sua remuneração. Nesse contexto, a forma de realizar o planejamento estratégico foi alterada.

Pelos documentos internos da empresa notou-se que, desde o início de 2003, havia a intenção de criar formas mais estruturadas para o planejamento estratégico. No entanto essa intenção ainda estava intercalada com uma série de elementos pouco estruturados e até bem humorados; como, por exemplo, nas recomendações gerais da direção para o planejamento estratégico: 'informalidade, descontração e humor, mas também, objetividade, clareza e especificidade nas colocações'. 
A ênfase no trabalho de planejamento, que na fase anterior a 2003 era direcionada apenas às áreas comerciais, passou a incluir efetivamente todas as áreas da empresa no ciclo e nas decisões estratégicas, abrindo a participação a todos os funcionários, alterando o que antes era exercício com ênfase maior no orçamento anual.

"Em 2003 a empresa se estruturou um pouco mais e percebeu-se a importância do envolvimento, né? Não tinha todo esse desdobramento com controle... a companhia sempre atingiu as suas estratégias, mas dessa forma ela é mais evidente e mais participativa, tem ações mais concretas e mais detalhadas” (Entrevistado 06).

Os planos criados pelas diversas áreas passaram a ser consolidados, e isso foi algo que facilitou e reforçou o controle da implementação do planejamento estratégico.

“Acho que a InfraCo se organizou melhor... Não sei se é por causa do Prêmio... começou um trabalho de acompanhar indicadores, de acompanhar efetivamente os planos de ação e colocar isso de uma maneira mais estruturada" (Entrevistado 13).

Esta mudança acabou incluindo, gradativamente, novas práticas na empresa e um alinhamento mais forte com uma instituição que confere um prêmio a empresas que aplicavam modelos de gestão de excelência e qualidade. Esse prêmio era concedido conforme os preceitos definidos e difundidos pela própria instituição, que atribui a premiação.

A mudança se configurou como crescente formalização da gestão da organização, de uma forma geral. No que tange às práticas utilizadas no planejamento estratégico, houve a definição de um padrão com temas a serem cobertos pela estratégia, análises formais que deveriam ser realizadas, o reforço do acompanhamento e controle dos resultados.

O planejamento estratégico só alcançou um formato estável no início do ano de 2005. A partir desse ponto, o planejamento foi descrito como mais organizado e focado durante sua elaboração e, efetivo para implementação e avaliação, sendo elogiado em algumas entrevistas. Porém, contrariando a ideia da efetividade na sua implementação, alguns entrevistados mostraram desconforto com o excesso de planos gerados, o que criou uma situação difícil de controlar, como um dos entrevistados comentou:

"Uma coisa bem marcante foi o excesso. Você tem muita... possibilidade de criar eventos de controle... Tem muito. E índices né? Teve um momento que... ficou um negócio de 60 linhas. Um negócio incontrolável. Aí você não consegue controlar, e durante o ano... 'Começou?' 'Não'. 'Então adia'. E só fazia... [risos] Acho que isso deve acontecer em toda empresa. Você tem aquelas metas e planos e não tem uma ação. Você fica tomado pelo seu dia-a-dia, quando vê... 'Ih! Adia aí!’” (Entrevistado 01).

Alguns entrevistados também consideraram que havia um engessamento da prática que perdeu sua flexibilidade, o que acabou barrando a criatividade e, algumas vezes, tornava a formulação de estratégias em preenchimento de informações requisitadas nos frames criados.

"Você começa a diminuir o estímulo à criatividade, o estímulo à inovação, o estímulo a novas iniciativas, porque as pessoas não estão totalmente preparadas pra isso. A gente se deparou com isso aqui internamente" (Entrevistado 14).

"E aí, o que acontece? Aquela reunião de brainstorming, onde você levanta tudo isso, ela acaba virando uma reunião de preencher frame. A diferença que a gente sente... a gente que é mais operacional e fica ali para anotar as coisas, é assim... Absurda! Nas primeiras reuniões, nos primeiros exercícios que eu participei, eu comecei a participar em 2002, dos exercícios de planejamento estratégico, era até difícil para eu anotar as ideias deles, porque era muita coisa, eu não entendia. Eu anotava de qualquer jeito, depois eu ia falar com eles... E nessas últimas eles já dão a frase do jeito que eles querem que você preencha lá” (Entrevistado 07).

Apesar dos contratempos enfrentados no cotidiano da empresa, após esse esforço de estruturação de sua gestão, a empresa recebeu a premiação. Um ano depois, época da coleta de dados, o planejamento estratégico foi descrito pelos entrevistados como o mais flexível desde o começo da introdução das práticas formais nos anos anteriores. 


\section{Analisando fases do planejamento da InfraCo}

Os dados obtidos mostram pontos de destaque nos quais ocorrem grandes mudanças no formato do planejamento e, principalmente, a variação de sua característica (in)formal, o que nos habilita a apontar diferentes fases dessa prática, ao longo da história da InfraCo. Estas fases foram provocadas por momentos emblemáticos de mudança dentro da empresa: (a) declínio das taxas de crescimento da empresa em meados da década de 1970; (b) fim da consultoria de planejamento estratégico no início de 1980; (c) mudança nos rumos do negócio em 1991, (d) três fatores que impactaram os resultados em 2002-2003; (e) recebimento do prêmio pelo modelo de gestão em 2007.

A Figura 1 ilustra estas mudanças em relação à formalização ocorrida na prática do planejamento estratégico. A figura representa uma interpretação do pesquisador, está fora de escala e a linearidade é utilizada por motivos didáticos.

A fase 1 pode ser caracterizada pela gênese do planejamento na empresa. Seu início ocorre a partir da diminuição das taxas de crescimento do negócio e os principais diretores da empresa elaboraram os primeiros planos estratégicos e exploraram o tema do planejamento estratégico.

Cerca de dez anos depois, o impacto do ano de 2002-2003 derivado de um incomum prejuízo da empresa (o segundo ano em 40 anos de história) configurou uma nova fase. Nesse período a prática de planejamento da organização entrou em um processo de formalização crescente, que se estabilizou em 2005. Esta fase foi caracterizada por forte expansão do número de profissionais envolvidos na formulação das estratégias, criação de instâncias de controle, aplicação de ferramentas e práticas para formulação e controle da implementação de planos estratégicos.

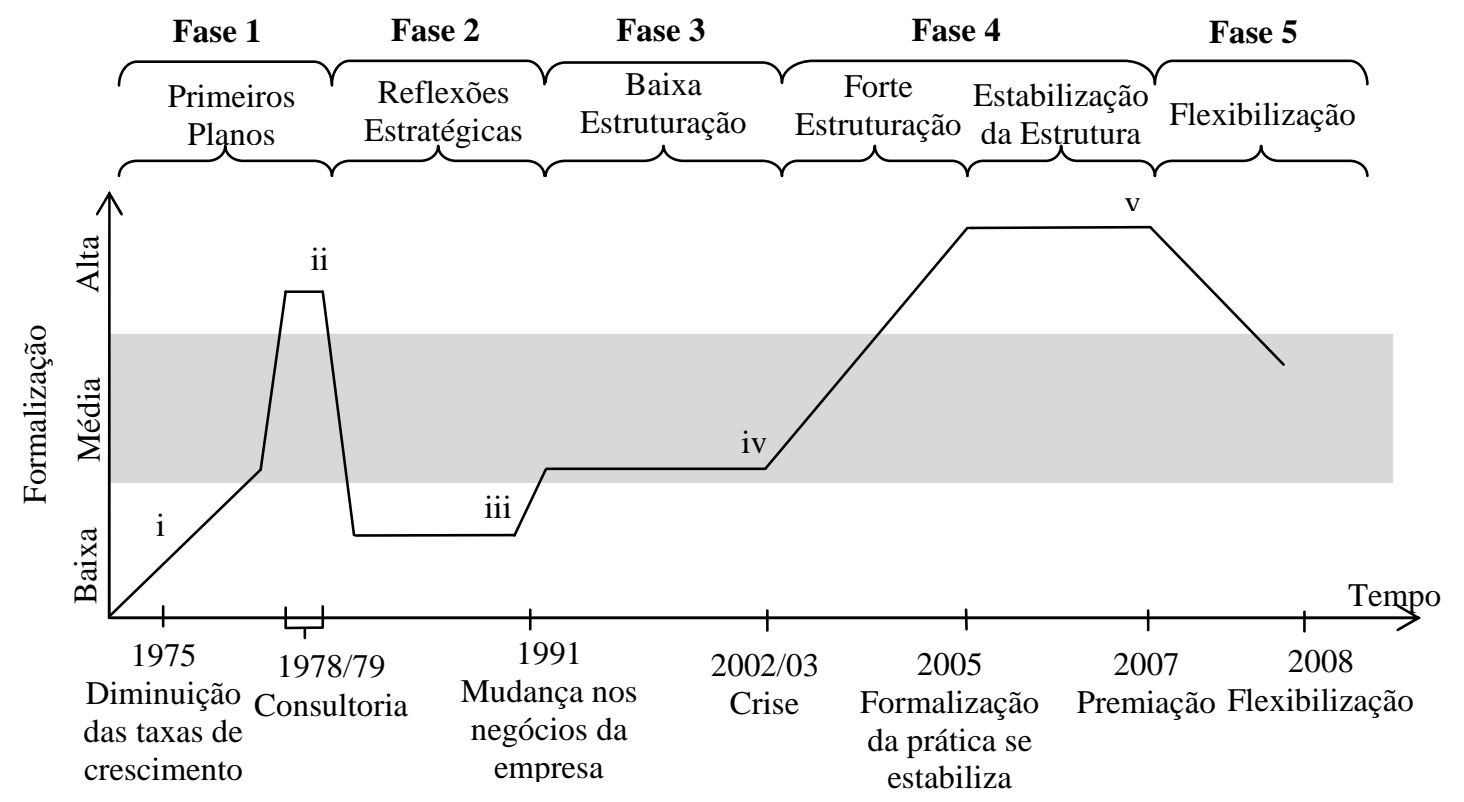

Figura 1. Formalização da Prática de Planejamento Estratégico.

Fonte: Elaborado pelo autor.

Consideramos compreensível esta reação de flexibilização das práticas porque, apesar de nenhum entrevistado ser completamente contra as práticas de planejamento e os processos criados no período, foi possível identificar nos relatos aspectos positivos e negativos das alterações no planejamento estratégico. Estes aspectos nutriram um debate interno sobre os benefícios e contratempos do novo formato do planejamento estratégico e das práticas aplicadas a ele. Isso nos possibilitou perceber uma polarização entre profissionais que exaltam as práticas de gestão e aqueles que mantêm uma postura mais crítica. Estas posições foram sustentadas por pessoas de diferentes áreas da empresa; nem mesmo entre os profissionais responsáveis pela gestão do ciclo de planejamento encontramos uma uniformidade. 
Após o prêmio ter sido auferido, a empresa entrou em nova fase, que foi caracterizada pela alteração nas ferramentas e práticas de estratégia, que tiveram uma redução na sua rigidez em favor de aspectos de reflexão mais amplos sobre estratégia. Esse movimento não foi restrito às práticas de estratégia, mas parece ter tido reflexo na empresa como um todo. Como o presidente da InfraCo mencionou em uma reunião em relação ao prêmio: "Estamos passando por uma ressaca".

Tabela 3

\section{Características das Fases do Planejamento Estratégico e Exemplo de Dados Relevantes}

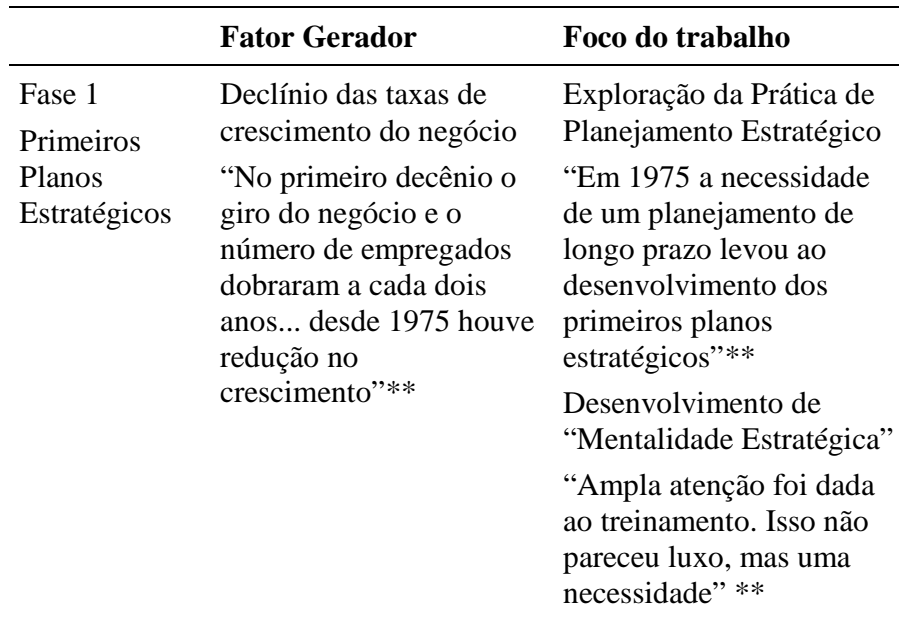

Fase 2 Resultados Ambíguos do

Reflexões Projeto da consultoria de Estratégicas planejamento estratégico

"Quando se olhou o número de horas de trabalho, percebeu-se o grande investimento feito" **

"havia quase um cinismo quando as decisões eram postergadas, propostas não eram analisadas"**

Fase 3 Mudança nos rumos do Baixa negócio.

Sem evidências Características

Baixo impacto na implementação dos primeiros planos

"O primeiro plano não teve muito impacto nas decisões da empresa. O segundo plano de desenvolvimento foi aperfeiçoado e mais elaborado, mas não mudou as coisas"**

Contratação de consultores

"a InfraCo crescera e tornara-se internacional, assumia novos riscos num ambiente de mudanças rápidas e imprevisíveis mudanças. Foi quando a companhia convidou consultores para desenvolver um programa de administração estratégica"*** Participação

"o novo plano estratégico foi formulado com amplo envolvimento do primeiro e segundo escalão da empresa, os principais executivos de áreas e o board"**

Importância Reduzida dos Planos Formais

"apesar de tempo e energia gastos nas análises das várias fases do processo de planejamento, $\mathrm{o}$ documento final - o plano - nunca foi formalmente emitido. Pouquíssimas pessoas envolvidas ficaram desapontadas por isso"***

Planejamento Contínuo (incremental)

"Essa omissão [dos planos formais] é uma indicação positiva do sucesso do processo: o fato que o planejamento ainda está acontecendo"*** "o sentimento é que nos aproximamos de um planejamento em tempo real"**

Direcionado à decisão de quais mercados atuar

"era muito focado em "que mercado nós vamos atacar? Que oportunidades que a gente vai perseguir?"*. (E01)

\section{Formato flexível}

"Ele era bem mais livre e eu acho que no final acabava ficando um pouco na cabeça de cada gestor a formulação"* (E10) em 1991... Nessa época que era justamente uma transição... o primeiro planejamento estratégico foi uma transição de mudança de público para privado"* (E01)
"Eram coisas com bastante brainstorming, mas liberdade total. Não tinha nem formato. Você desenvolvia, não tinha nada estruturado.... muito informal"* (E01)

Baixa Preocupação com Controle de Implementação

"Mas no passado a coisa era mais solta. Você não tinha esse movimento de consolidação, cada unidade tinha oportunidade para acompanhar o seu planejamento, a coisa não era tão efetiva assim"* (E11)

Áreas não comerciais com foco em orçamento

"Acho que existia na empresa que está se modificando é a superposição de planejamento estratégico com orçamento... o peso era mais no orçamento"*. (E01) 
Tabela 3 (continuação)

\begin{tabular}{|c|c|c|c|}
\hline & Fator Gerador & Foco do trabalho & Características \\
\hline \multirow{12}{*}{$\begin{array}{l}\text { Fase } 4 \\
\text { Forte } \\
\text { Formalização }\end{array}$} & $\begin{array}{l}\text { Problemas em um projeto } \\
\text { da empresa }\end{array}$ & \multirow{12}{*}{$\begin{array}{l}\text { Planejamento é Ampliado } \\
\text { para Todas as Áreas da } \\
\text { Empresa. } \\
\text { “[a preocupação voltou-se] } \\
\text { muito mais para uma } \\
\text { estruturação da empresa } \\
\text { como um todo com a } \\
\text { gestão dela mesma } \\
\text { propriamente dita”* (E05) }\end{array}$} & $\begin{array}{l}\text { Planejamento Estratégico Ligado à Idéia de Gestão } \\
\text { de Qualidade }\end{array}$ \\
\hline & “em 2002/03 ela tomou & & "Nós vamos ter uma gestão de primeiríssima linha". \\
\hline & $\begin{array}{l}\text { esse susto por conta de } \\
\text { uma obra... que acabou } \\
\text { levando uma grande parte } \\
\text { do nosso patrimônio"** } \\
\text { (E13) }\end{array}$ & & $\begin{array}{l}\text { Uma gestão empresarial, uma gestão de primeiro } \\
\text { mundo, então, pra se enquadrar nisso no início, você } \\
\text { precisa ter... o ciclo de planejamento estratégico, por } \\
\text { exemplo, o ciclo de planejamento estratégico é } \\
\text { fundamental"* (E09) }\end{array}$ \\
\hline & \multirow{5}{*}{$\begin{array}{l}\text { Estouro da bolha da } \\
\text { internet } \\
\text { "na mesma época a } \\
\text { InfraCo não foi bem } \\
\text { sucedida nos negócios de } \\
\text { internet que tinha } \\
\text { entrado"* (E14) }\end{array}$} & & Ampliação da Participação \\
\hline & & & \multirow{5}{*}{$\begin{array}{l}\text { "a empresa se estruturou um pouco mais e percebeu- } \\
\text { se a importância do envolvimento dos profissionais" } \\
\text { (E09) } \\
\text { Reforço do Controle de Implementação } \\
\text { "passamos desenrolar os planos de uma maneira } \\
\text { prática e depois acompanhar isso com os } \\
\text { indicadores"* (E13) }\end{array}$} \\
\hline & & & \\
\hline & & & \\
\hline & & & \\
\hline & Fatores macroeconômicos & & \\
\hline & \multirow{3}{*}{$\begin{array}{l}\text { "O presidente indicou o } \\
\text { impacto negativo das } \\
\text { condições } \\
\text { macroeconômicas"* } \\
(\text { E07) }\end{array}$} & & $\begin{array}{l}\text { "Não tem essa de não acompanhar os planos de ação, } \\
\text { de não acompanhar os indicadores"* (E05) }\end{array}$ \\
\hline & & & Padrão de Linguagem \\
\hline & & & $\begin{array}{l}\text { "foi um movimento de trazer todo mundo para a } \\
\text { mesma linguagem"* (E13) }\end{array}$ \\
\hline Fase 5 & Premiação & Similar à fase anterior & Alterações das Práticas do Planejamento \\
\hline \multirow[t]{4}{*}{ Flexibilização } & \multirow{4}{*}{$\begin{array}{l}\text { Comentário do presidente } \\
\text { sobre a ressaca após a } \\
\text { premiação, na qual os } \\
\text { processos da empresa } \\
\text { foram flexibilizados } * * *\end{array}$} & & $\begin{array}{l}\text { "Até o ano passado era um template ligeiramente } \\
\text { diferente. Eu achei esse aqui mais interessante de } \\
\text { nele se trabalhar"* (E10) }\end{array}$ \\
\hline & & & $\begin{array}{l}\text { "esse foi o mais simples de todos. Até agora esse foi } \\
\text { o mais fácil"* (E01) }\end{array}$ \\
\hline & & & Flexibilização das Análises \\
\hline & & & $\begin{array}{l}\text { Relativização da necessidade de análises de todas as } \\
\text { perspectivas, ampliação das análises baseadas em } \\
\text { reflexões sobre o ambiente em contraposição } \\
\text { exclusividade de construção de planos*** }\end{array}$ \\
\hline
\end{tabular}

Nota. Legenda (fonte de dados): * Entrevistas; ** Documentos interno; *** Observação direta.

Fonte: Elaborado pelo autor.

Essa polarização de prós e contras é complexa e pode-se observar trade-offs, ou talvez, situações aparentemente paradoxais. Um exemplo é o benefício da padronização da linguagem e conteúdo para facilitar a comunicação interna e construção de uma estratégia coesa na empresa, tendo como contrapartida o engessamento do processo de planejamento e a falta de liberdade para decidir quais informações utilizar e inserir nas estratégias definidas.

Porém é importante destacar que, mesmo em fase de ressaca, essa polarização de percepções gera uma luta que molda continuamente a prática do planejar na organização em sua dinâmica social. Enquanto alguns agentes têm saudade de pontos que foram flexibilizados, outros identificam novos pontos críticos nas ferramentas formais, recursivamente definindo a prática de planejamento estratégico em suas interações.

\section{Discussão}

A análise contingencial conduz à seguinte dedução: em organizações baseadas em projetos que atuam em ambiente instável, a definição das estratégias é pouco estruturada e se sustenta fortemente 
em processos emergentes, em contraposição a processos deliberados (Mintzberg \& McHugh, 1985), aproximando-se da noção de estratégia trabalhada pela escola de aprendizagem ( $c f$. Mintzberg, Ahlstrand, \& Lampel, 2000). Esse tipo de definição seria praticamente um reflexo da estrutura flexível da empresa que, pelas análises da perspectiva contingencial é coerente com: (a) a turbulência de seu ambiente que apresenta ciclos irregulares de investimento em infraestrutura (Lawrence \& Lorsch, 1973); (b) a consequente incerteza em seus negócios (Burns \& Stalker, 1961); (c) a característica customizada dos serviços prestados pela empresa, que são flexíveis para atender às necessidades do cliente; e (d) o emprego de tecnologias de ponta (Woodward, 1977).

Percebe-se em nosso estudo de caso que estas ideias têm eco na InfraCo: verificou-se, de forma clara, uma aversão de alguns profissionais ao aumento de formalização na prática de planejamento, além de se identificar a importância dada a processos emergentes na estratégia da empresa. Partindo dessa análise, poderíamos ser levados a concluir que, realmente, empresas organizadas por projetos não deveriam estruturar seu planejamento. No entanto, ao observar as modificações na forma de realização do planejamento estratégico ao longo do tempo, percebe-se que esforços de formalização marcaram a prática de planejamento, deixando estruturas que continuaram a ser concretizadas pelos agentes em sua interação.

Assim, ao analisar a história da prática de planejamento estratégico sobre a ótica da teoria da estruturação, pode-se interpretar que a modalidade (Giddens, 1984) planejamento estratégico sofreu alterações. Cada um dos eventos identificados na Figura 1 é uma espécie de gatilho para a ocorrência de eventos na interação dos agentes que, cumulativamente, deslocaram a prática de planejamento, isto é, incluíram novos procedimentos formais de trabalho (recursos) e discursos (regras) (Barley \& Tolbert, 1997; Jarzabkowski, 2008). Esta dinâmica propiciou a mudança das estruturas que restringem e habilitam o planejar na organização.

Ao serem comparadas as fases 1 e 2 com as fases 4 e 5, percebe-se que os processos de formalização que ocorreram nos primeiros períodos ( 1 e 4) foram considerados inadequados e tidos como excesso. Essa percepção derivou da frustração dos profissionais que se desgastaram no desenvolvimento dos planos e, frequentemente, não viam a sua efetividade no momento de implementação. Essa frustração na interação dos agentes parece ser o gérmen do retorno a um formato menos formalizado de planejamento, ocorrido nas fases subsequentes ( 2 e 5). Aparentemente, a fase 3 foi uma exceção a essa dinâmica de retorno a práticas menos formalizadas, mas devemos ressaltar a escassez de dados entre 1991 e 2000 para apoiar essa percepção.

Em todos os períodos de mudança, marcados pelos eventos, ocorreu a criação de estruturas: regras e recursos, como a criação de um pensamento estratégico, aplicação de discursos da excelência, o uso de ferramentas de análise de portfólio, definição de perspectivas estratégicas e estruturas de análise (e.g. SWOT). Mesmo que a redução na formalização represente um movimento de retorno a estruturas menos formais, há resquícios da fase anterior que se mantêm em movimento pelos agentes, que continuam concretizando as estruturas por perceberem benefícios econômicos: e.g. eficiência pela redução de tempo de trabalho; e simbólicos: e.g. justificação da análise feita aos superiores; ou mesmo pela interiorização dessas estruturas pelos agentes (Giddens, 1984).

Por esta perspectiva, pode-se entender que a escolha de um caminho para a formulação da estratégia não é exclusivamente relacionada a determinadas características da organização (e.g. ambiente), mas à dinâmica social na qual a estratégia é criada, e cuja composição é dada pela relação tríplice entre práxis, profissionais e, práticas e ferramentas de gestão (Jarzabkowski et al., 2007; Whittington, 2006). Dessa forma, se olharmos o panorama da InfraCo, é possível identificar um incremento na formalização de procedimentos de gestão de seu planejamento estratégico, constatação que contraria os quadros analíticos contingenciais que indicariam um nível baixo de formalização de procedimentos e rotinas. A análise indica um processo de estruturação do planejamento estratégico que têm como fator central a dinâmica social da organização.

Esta ideia parece próxima daquela apresentada por Mintzberg (1978) de momentum burocrático, noção tributária da física e originariamente conceitua a quantidade de movimento de determinado 
objeto. Em uma tradução mais popular, poderíamos chamar de embalo, uma metáfora interessante para descrever os resultados da dinâmica social, que pode direcionar a forma de trabalhar a estratégia naquele contexto.

No entanto a noção momentum burocrático não explica o processo social que subjaz nesse movimento (i.e. momentum) da organização que, em dentro de análises baseadas na teoria da estruturação, podem ser explicadas, na "relação entre contexto institucional, estrutura dos relacionamentos e práticas (atividades) estratégicas aponta para a mútua dependência entre esses elementos ... marcada por contradições institucionais" (Maciel \& Machado-da-Silva, 2009, p. 1275). Dessa forma, este estudo buscou destacar que este processo social é permeado por disputas entre agentes com posições distintas em relação ao trabalho de definição de estratégias, e à forma de concretização de estruturas ligadas ao planejamento na interação dos profissionais.

Esses agentes interagem constantemente, seja para a própria definição da estratégia da empresa seja para o preenchimento das análises do ciclo anual. Essa interação recursiva gera uma luta sobre qual deve ser o direcionamento do trabalho. Enquanto, por um lado, alguns fazem a defesa do controle da implementação da estratégia, por outro, há a ideia de estratégia sendo o como fazer e ser competitivo.

A luta ocorre porque os entendimentos distintos sustentados pelos agentes sobre o que é planejar a estratégia, quais são os resultados esperados do ciclo e como isso deve ser feito, são decisivos para a definição do seu trabalho como estrategista. Cada qual quer que sua verdade defina o planejamento. Assim, sugere-se que o pressuposto contingencial deve ser ponderado em relação a esse movimento e, principalmente, à dinâmica subjacente da organização na qual são definidos socialmente os critérios técnicos ligados à estratégia e seu planejamento, uma vez que estes não existem de forma concreta (Meyer \& Rowan, 1977).

Em consonância com os estudos da abordagem de estratégia como prática, nossa análise não entra no dilema entre conteúdo e processo de estratégia (Chia \& Mckay, 2007). Ao invés de entender que a prática de estratégia da empresa é definida por práticas formais de planejamento, ou exclusivamente definida em processos emergentes, indicamos que o enfoque das análises sobre a estratégia das organizações deve direcionar-se à sua dinâmica social. A definição sobre o que é o trabalho de estratégia e como ele deve (ou não) ser desempenhado está em constante construção e disputa, sendo, portanto, uma definição que emerge eminentemente de sua estruturação histórica, na interação dos agentes com as estruturas, sofrendo alterações pela recursividade entre estas instâncias na prática do planejamento estratégico.

\section{Comentários Finais}

Apesar de buscarmos procedimentos metodológicos que fornecessem segurança para as análises, como o uso de múltiplos métodos de coleta de dados, a pesquisa apresenta algumas limitações. Nosso estudo sobre a prática teve um acesso escasso a observações diretas, sendo a maior parte das análises provenientes de relatos dos profissionais e documentos sobre a formação de estratégia na empresa. Assim, neste trabalho lidamos, principalmente, com a leitura dos profissionais sobre sua prática cotidiana e suas ferramentas e procedimentos formais/informais, durante a formulação da estratégia, e com os dados deixados em documentos internos e públicos. Outra limitação é relativa à cobertura dos dados. Apesar de nossa análise longitudinal cobrir uma história de aproximadamente 30 anos, temos um período em que há poucas fontes significativas de dados (19851991); e um período em que apenas os relatos dos entrevistados sustentam as análises (1991-2001). Por fim, toda a análise dos dados se ampara fortemente nas percepções de um único pesquisador.

Apesar destas limitações, a pesquisa apresenta algumas contribuições. A principal delas foi evidenciar que, independentemente do caso estudado ser uma empresa organizada por projetos, houve esforços e estruturação da prática de planejamento estratégico, algo não esperado pelas análises 
contingenciais. Responder categoricamente se a criação de estruturas formais de planejamento estratégico é adequada a empresas com esta estrutura, baseada em projetos, em ambiente instável não é tarefa simples. Entendemos que responder a esta questão só seja possível a partir de uma análise da estruturação do contexto social da organização. Partindo deste pressuposto, destacamos a necessária ponderação do arcabouço analítico contingencial (constitutivo da maior parte das análises de formação estratégica), a partir da análise da dinâmica social da organização, que apresenta diferentes reações dos profissionais a mudanças e ferramentas de planejamento, engendrando uma luta em torno dos significados ligados à prática de planejamento.

Assim, pela análise da estruturação das práticas de planejamento estratégico, pudemos ilustrar como os profissionais receberam e negociaram esse processo dentro da organização. Isso se configura como contribuição, porquanto, apesar de muitos estudos identificarem a existência de pressões institucionais, raramente é apresentada essa perspectiva da prática, principalmente apontando a questão da disputa interna e agência dos profissionais sobre o planejamento estratégico (Heugens \& Lander, 2009).

Nossa análise ainda apresenta implicações para a prática dos profissionais nas organizações. Consideramos que a principal delas se dirige à questão das mudanças. Apesar da possibilidade de alguns esforços de mudança serem tidos como malsucedidos em análises de curto prazo, há a possibilidade de permanência de alguns aspectos dos esforços de realizados, promovendo diferenças sutis, mas que podem ser relevantes para o desenvolvimento da organização no longo prazo.

\section{Artigo recebido em 07.09.2010. Aprovado em 03.05.2011.}

\section{Agradecimentos}

O autor agradece o professor Thomaz Wood Jr. pela orientação na dissertação de mestrado da qual este artigo deriva, como também o CNPq e a CAPES pelo auxílio financeiro que viabilizou o projeto. Igualmente, agradece os comentários dos professores Marcelo Marinho Aidar, Rafael Alcadipani da Silveira, Alexandre Faria e dos avaliadores anônimos desta revista. Especialmente, o autor agradece Mario Aquino Alves e Marcus Vinícius Gomes pelo apoio e contribuições à análise contida no artigo.

\section{Referências}

Andrews, K. R. (1971). The concept of corporate strategy. Homewood: DowJonesIrwin.

Ansoff, I. (1965). Corporate strategy. New York: Mcgraw-Hill.

Arksey, H., \& Knight, P. (1999). Interviewing for social scientists. Londres: Sage.

Balogun, J., \& Johnson, G. (2005). From intended strategies to unintended outcomes: the impact of change recipient sensemaking. Organization Studies, 26(11), 1573-1601. doi: $10.1177 / 0170840605054624$

Barley, S., \& Tolbert, P. (1997). Institutionalization and structuration: studying the links between action and organization. Organization Studies, 18(1), 93-117. doi: $10.1177 / 017084069701800106$

Barney, J. (1986a). Strategic factor markets: expectations, luck and business. Strategy Management Science, 32(10), 1231-1241. doi: 10.1287/mnsc.32.10.1231

Barney, J. (1986b). Types of competition and the theory of strategy: toward an integrative framework. Academy of Management Review, 11(4), 791-800. doi: 10.2307/258397 
Bitektine, A. (2008). Prospective case study design: qualitative method for deductive theory testing. Organizational Research Methods, 11(1), 160-180. doi: 10.1177/1094428106292900

Burns, T., \& Stalker, G. (1961). The management of innovation. Londres: Tavistock.

Carter, C., Clegg, S., \& Kornberger, M. (2008). Strategy as practice? Strategic Change, 6(1), pp. 8399. doi: $10.1177 / 147612700708715$

Chandler, A. D. (1962). Strategy and structure. Cambridge: MIT Press.

Chia, R., \& Mckay, B. (2007). Post processual challenges for the emerging strategy-as-practice perspective. Human Relations, 60(1), 217-242. doi: 10.1177/0018726707075291

Child, J. (1972). Organizational structure, environment and performance: the role of strategic choice. Sociology, 6(1), 1-22. doi: 10.1177/003803857200600101

Cohen, I. (1987). Structuration theory and social practice. In A. Giddens \& J. Turner (Eds.), Social Theory Today (pp. 273-308). Cambridge: Polity Press.

Czarniawska, B. (2008). Organizing: how to study it and how to write about it. Qualitative Research in Organizations and Management, 3(1), 4-20. doi: 10.1108/17465640810870364

Dijk, T. van (2000). Cognição, discurso e interação. São Paulo: Contexto.

DiMaggio, P. J., \& Powell, W. W. (1983). The iron cage revisited: institutional isomorphism and collective rationality in organizational fields. American Sociological Review, 48(2), 147-160. doi: $10.2307 / 2095101$

Donaldson, L. (2001). The contingency theory of organizations. Londres: SAGE.

Dyer, W., \& Wilkins, A. (1991). Better stories, not better constructs, to generate better theory: a rejoinder to eisenhardt. Academy of Management Review, 16(3), 613-619. doi: 10.2307/258920

Eisenhardt, K. (1989). Building theories from case study research. Academy of Management Review, 14(4), 532-550. doi: 10.2307/258557

Eisenhardt, K., \& Graebner, M. (2007). Theory building from cases: opportunities and challenges. Academy of Management Journal, 50(1), 25-32. doi: 10.2307/20159839

Ferreira, P. C. G., \& Malliagros, T. G. (1997). O impacto da infra-estrutura sobre o crescimento da produtividade do setor privado e do produto brasileiro. Ensaios Econômicos da EPGE, (315), 128.

Flyvbjerg, B. (2006). Five misunderstanding about case-study research. Qualitative Inquiry, 12(2), 219-245. doi: 10.1177/1077800405284363

Ghemawat, P. (2002). Competition and business strategy in historical perspective. Business History Review, 76(1), 37-74. doi: 10.2307/4127751

Giddens, A. (1984). The constitution of society. Berkeley: University of California Press.

Grant, R. (2003). Strategic planning in a turbulent environment: evidence from the oil majors. Strategic Management Journal, 24(6), 491-517. doi: 10.1002/smj.314

Heugens, P., \& Lander, M. (2009). Structure! Agency! (and other quarrels): a meta-analysis of institutional theories of organization. Academy of Management Review, 52(1), 61-85.

Jarzabkowski, P. (2005). Strategy as practice. London: Sage. 
Jarzabkowski, P. (2008). Shaping strategy as structuration process. Academy of Management Journal, 51(4), 621-650.

Jarzabkowski, P., Balogun, J., \& Seidl, D. (2007). Strategizing: the challenges of the practice perspective. Human Relations, 60(1), 5-27. doi: 10.1177/0018726707075703

Jarzabkowski, P., \& Wilson, D. (2006). Actionable strategy knowledge: a practice perspective. European Management Journal, 24(5), 348-367. doi: 10.1016/j.emj.2006.05.009

Jick, T. (1979). Mixing qualitative and quantitative methods: triangulation in action. Administrative Science Quarterly, 24(4), 602-611. doi: 10.2307/2392366

Johnson, G. (1987). Strategic change and the management process. Oxford: Blackwell.

Knott, P. (2006). A typology of strategy tool applications. Management Decision, 44(8), 1090-1105. doi: 10.1108/00251740610690630

Langley, A. (1999). Strategies for theorizing from process data. Academy of Management Review, 24(4), 691-710. doi: 10.2307/259349

Lawrence, P., \& Lorsch, J. (1973). As empresas e o ambiente. Petrópolis: Vozes.

Lofland, J., \& Lofland, L. (1995). Analyzing social settings. Belmont: Wadsworth Publishing.

Machado-da-Silva, C., Fonseca, V., \& Crubellate, J. M. (2005). Estrutura, agência e interpretação: elementos para uma abordagem recursiva do processo de institucionalização [Edição Especial]. Revista de Administração Contemporânea, 9, 9-39. doi: 10.1590/S1415-65552005000500002

Maciel, C., \& Machado-da-Silva, C. (2009). Práticas estratégicas em uma rede de congregações religiosas: valores e instituições, interdependência e reciprocidade. Revista de Administração Pública, 43(6), 1251-1278. doi: 10.1590/S0034-76122009000600003

March, J. G. (1991). Exploration and exploitation in organizational learning. Organization Science, 2(1), 71-87. doi: $10.1287 /$ orsc.2.1.71

Meyer, M., \& Rowan, B. (1977). Institutionalized organizations: formal structure as myth and ceremony. The American Journal of Sociology, 83(2), 340-363. doi: 10.2307/2778293

Miles, M., \& Huberman, A. (1994). Qualitative data analysis. Thousand Oaks: Sage.

Mintzberg, H. (1978). Patterns in strategy formation. Management Science, 24(9), 934-948. doi: 10.1287/mnsc.24.9.934

Mintzberg, H. (1993). Structures in fives. Englewoods Cliffs: Prentice Hall.

Mintzberg, H. (1994). The rise and fall of strategic planning. New York: The Free Press.

Mintzberg, H., Ahlstrand, B., \& Lampel, J. (2000). Safári de estratégia. Porto alegre: Bookman.

Mintzberg, H., \& McHugh, A. (1985). Strategy formation in an adhocracy. Administrative Science Quarterly, 30(2), 160-197.

Mintzberg, H., \& Waters, J. (1985). Of strategies, deliberate and emergent. Strategic Management Journal, 6(3), 257-272. doi: 10.2307/2486186

Orlikowski, W. J. (2000). Using technology and constituting structures: a practice lens for studying technology in organizations. Organization Science, 11(4), 404-428. doi: 10.1287/orsc.11.4.404.14600 
Penrose, E. (1959). The theory of the growth of the firm. New York: Wiley.

Pettigrew, A. (1985). Awakening giant: continuity and change on ICI. Oxford: Blackwell.

Porter, M. (1980). Competitive strategy. New York: Free Press.

Rigby, D., \& Bilodeau, B. (2007). Bain's global 2007 management tools and trends survey. Strategy and Leadership, 35(5), 9-16. doi: 10.1108/10878570710819161

Rose, R. (2006). A proposal for integrating structuration theory with coordinated management of meaning theory. Communication Studies, 57(2), 173-196. doi: 10.1080/10510970600666867

Rumelt, R. (1974). Strategy, structure and economic performance. Boston: HBS Press.

Rumelt, R., Schendel, D., \& Teece, D. (Eds.). (1994). Fundamental issues in strategy. Boston: HBS Press.

Schatzki, T. R., Knorr-Cetina, K., \& Savigny, E. (2001). The practice turn in contemporary theory. Londres: Routledge.

Selznick, P. (1966). TVA and the grass roots. New York: Harper Row.

Siggelkow, N. (2007). Persuasion with case studies. Academy of Management Journal, 50(1), 20-24. doi: $10.2307 / 20159838$

Spink, P. K. (1999). Análise de documentos de domínio público. In M. J. P. Spink (Org.), Práticas Discursivas e Produção de Sentidos no Cotidiano (pp. 123-151). São Paulo: Editora Cortez.

Vasconcelos, F., \& Cyrino, A. (2000). Vantagem competitiva: os modelos teóricos atuais e a convergência entre estratégia e teoria organizacional. Revista de Administração de Empresas, 40(4), 20-37.

Weick, K. (1979). Social psychology of organizing. New York: McGraw-Hill.

Wernerfelt, B. (1984). A resource-based view of the firm. Strategic Management Journal, 5(2), 171180. doi: $10.1002 / \mathrm{smj} .4250050207$

Whittington, R. (1996). Strategy as practice. Long Range Planning, 29(5), 731-735. doi: 10.1016/0024-6301(96)00068-4

Whittington, R. (2006). Completing the practice turn in strategy research. Organization Studies, 27(5), 613-634. doi: 10.1177/0170840606064101

Woodward, J. (1977). Organização industrial. São Paulo: Atlas. 